value, namely, pickles. In 1941, therefore, it has been decided to plant several thousand acres of land with onions for pickling, with garlic, cauliflower, gherkins, red cabbage and mustard. Will science say that the decision is wrong?

When the figures are compared side by side, green vegetables are more substantial providers of vitamin C than any fruit except black currant. Thus in war. time they can readily take the place of the oranges and lemons which no longer reach us. According to the analytical figures for carotene, besides supplying the full physiological requirement of vitamin $C$, green vegetables can also provide all the vitamin A we need. Here is, however, a topic on which further investigation is required. To what extent is the carotene present in each plant physiologically active as vitamin $\mathrm{A}$, and what proportion is absorbed by the body? Even if only 40 per cent of the carotene present in a $4-\mathrm{oz}$. portion of watercress is physiologically available, it will still provide 50 per cent of the total daily requirement. In spite of the lack of clear-cut evidence on the vitamin A activity of each vegetable, there are, therefore, grounds for asserting that the full vitamin A needs of the body could be supplied by vegetables should circumstances ever require it.

Besides their importance as protective foods, vegetables could play other minor parts in war-time nutrition. A temporary glut of carrots, for example, if dried would provide palatable carbohydrate. Although perhaps more physiological work is needed on the biological value of green leaf protein, Sir John Russell, from the chair, agreed with the weight of current scientific opinion that its value is high Preparation of purified vegetable protein might thus provide a valuable addition to the national food supply.

The Society of Chemical Industry's discussion showed that many lacunæ in the knowledge of the nutritive value of vegetables exist. Planning of vegetable production even when guided by scientific advice is a difficult task which may never reach perfection. The crucial rôle of green vegetables is to provide almost alone in war-time the whole dietary requirement of vitamin C. Research on the physiological availability of leaf carotene is not of equal importance. Just as a population is immunized against typhoid for six months or more by a single treatment, so can a country be protected against vitamin A deficiency for a winter by a single dose. The daily requirement of vitamin $\mathrm{C}$, however, must be acquired daily. This is where work, investigation, inspection and analysis at every point must be organized. The Forces equally with the civil authorities must never be satisfied with calculations from a book of tables to insure the nutritional adequacy of food supplies. The men at a mess where the best scientific information had been applied to perfect their diet were found, when submitted to a saturation test, to be grossly deficient in vitamin C. Communal catering tends to increase the times during which dishes are kept hot, a process destructive of vitamin C.

The chemists met the botanists, the dietitians and the administrators to their mutual benefit. The national interest would be served by the further penetration of scientific workers into the market, the communal feeding centre and the canteen.

\title{
THE BRITISH PHARMACEUTICAL CONFERENCE
}

$\mathrm{T}^{\mathrm{H}}$ HE seventy-eighth annual meeting of the British Pharmaceutical Conference was held at Conway Hall, Red Lion Square, London, on April 16. With a single day, instead of the best part of a week as in peace-time, the proceedings were severely curtailed, but in addition to the chairman's address, twelve papers were presented at the science session, and although only summaries of them were actually read, the full papers will be available in the official publication of the Conference, in due course. Some of the papers are outlined below.

In his inaugural address as chairman, Mr. A. R. Melhuish dealt with problems affecting pharmacists in their capacity of servants of medicine and servants of the State. He spoke, to use his own phrase, as "a workaday practising pharmacist", and advised his colleagues that they would be doing more for the medical services of the country if they devoted more attention to those fields of activity which do not involve legislation, than if they spent time in striving for such politically unattainable goals as the reservation to them of the sale of all medicines. He impressed on them the importance of 'personality'; the greatest asset for the individual pharmacist in the future, he said, would be his individuality.

Two papers related to ergot. One of them, by C. H. Hampshire and M. W. Partridge, was from the laboratory of the British Pharmacopœia Commission, and the second, by N. L. Allport and N. R. Jones, from the laboratories of the British Drug Houses, Ltd. The first consisted of notes on the extraction and decomposition of the alkaloids; it showed that neither continuous extraction of ergot with methylene dichloride nor shaking ergot with menstruum of ammoniacal acetone completely extracts the alkaloids, which are completely extracted, however, by continuous extraction with anæsthetic ether. In the second paper, the authors described a rapid method for the determination of ergometrine and ergotoxine.

A paper, by H. Berry, from the College of the Pharmaceutical Society, on the components of acriflavine, was summarized by the author as follows : (I) the bacteriostatic value of the two active components and mixtures of these in varying proportions have been compared against certain organisms; the results show little variation; (2) there is no evidence of a bacteriostatic or physical character of any definite combination between the two components; (3) it is suggested that proflavine or the neutral hydrochloride of $2: 8$-diaminoacridine should replace acriflavine for surgical use.

A second paper, by F. Wokes, from the College of the Pharmaceutical Society, had as its subject "The Subcutaneous Implantation of Thyroxine Tablets". The author suggested that great caution be employed in the implantation of thyroxine tablets in human subjects, and that preference be given to the oral administration of thyroid, which appears to be much safer and more effective.

A paper, by A. M. Briggs and D. E. Callow, from the Evans Biological Institute, dealt with the 
preparation of sterile solutions of procaine hydrochloride. The author's conclusions are that sterile solutions can be prepared without the use of bacteriaproof filters, provided aseptic methods are used. Solutions prepared with an antiseptic present are not vulnerable to contamination likely to occur in a laboratory devoted to the production of sterile preparations. Solutions prepared with both an antiseptic present and an oxidation-preventive substance such as sulphur dioxide are even less vulnerable to contamination. The antiseptic properties of solutions of procaine hydrochloride tend to increase with increase of percentage strength.

A second paper, by G. E. Shaw and H. G. Hind, from the Evans Biological Institute, was on "Some Aspects of the Storage of Antitoxins During Wartime". Antitoxic serum, the blood serum of hyperimmunized animals, is issued for sale either in its natural state or, more usually, as a solution of a selected protein fraction therefrom; it is of special importance in war-time owing to the exposure of the population to risk from epidemic disease and the occurrence of a large number of injuries which necessitate antitetanic treatment. Antitoxin is stored in a sterile condition at about $4^{\circ} \mathrm{C}$. in large glass containers. In view of the risk from damage through enemy aerial activity, bulk storage presents a serious problem, owing to the possibility of containers breaking and the supply of electricity to the refrigerator plant being interrupted. The authors sought for a method which would eliminate the need for glass containers, and make the use of refrigeration unnecessary, but would, at the same time, preserve the potency and maintain the sterility of the product. They described two methods, each yielding a dry powder which may be stored in any type of container. The potency of the product is maintained. Cold-storage accommodation is unnecessary, and the powder is self-sterile. The desiccation method requires special apparatus for drying, but this does not involve a large capital outlay. The material contains so much preservative that, although reasonable care in handling is naturally adopted, complete asepsis is not essential.

\section{PHOTOPHORES IN DECAPOD CRUSTACEA}

$\mathrm{D}^{\mathrm{R}}$ R. DENNELL'S work on the structure of the photophores in certain decapod crustacea from deep water is of outstanding interest and importance*. It has been known for long that luminous organs exist in many of the deep-sea decapods; but it is astonishing to find such a variety of structure and so much difference in closely related forms.

The photophores described in this work are not all proved luminous organs, but morphological evidence makes it extremely likely that this is so. Only in a few cases have live animals been seen to emit light, but those who have observed the phenomenon have made careful notes of the position of the light organs, and in these cases it is certain that true photophores are present. The reason for the luminescence is still obscure. As in the squids and fish which possess them, the luminous organs mostly throw their light downwards, lighting an area outside the field of vision, it is especially difficult to understand why in nearly all species of Sergestids examined, and also in Parapandalus, some of the photophores should be situated in such a position that they must illumine the branchial chamber and throw light downwards on the gills. There is nothing in the structure of the gills themselves to show that they could benefit from such illumination, and it may be as is suggested (but with serious objections) that the development of light-organs here is simply the response to a rich oxygen supply.

Within the genus Sergestes no fewer than four different types of photophores are found : (1) The organs of Pesta which occur in the larger number of species and are modified liver tubules of endodermal origin; (2) complex organs with lenses scattered superficially on the body which are found in Sergestes challengeri and its allies; (3) superficial simple organs without lenses scattered over the body as in $S$. regalis (this being an entirely new type of luminous organ); (4) simple superficial streaks on the carapace which are found to be present in those species which also possess the organs of Pesta. The second and

* On the Structure of the Photophores of some Decapod Crustacea. By Dr. Ralph Dennell. Discovery Reports, 20, 307-382, plates XXIV-XXVI (1940). fourth of these are of ectodermal origin, the third may be ectodermal, or, possibly, mesodermal. It is shown that the structure of the photophores in the various species of Sergestes may be entirely different and that it is unsafe to conclude that any are similar unless the minute structure is examined, even if they are in the same position.

In Parapandalus richardi, which with some other pandalids possesses photophores outwardly like the main bodies of the organs of Pesta of Sergestids, these organs have a totally different minute structure. It is a remarkable fact that such similar organs should have been separately evolved in the two groups; it shows that they must subserve some important function, if, as yet, not sufficiently understood. There are also in Parapandalus organs on the pleopods which are doubtfully designated as photophores.

In the Hoplophorids the photophores have reached a very high state of complexity, and here again a variety of types is shown, movement being well developed. The pleopod organs are very similar in all the species of Hoplophorus and Systellaspis examined, but the other types occur very irregularly ; photophores in similar positions in two species are frequently entirely different in structure, while in a single species a number of different types of organ is to be found. For the most part the various kinds of organ are entirely distinct and they do not form stages in a developmental series. It is a remarkable fact that the luminous streak behind the fifth leg, which is a conspicuous feature in both Systellaspis and Hoplophorus, should have an entirely different structure in these two closely related genera.

The present investigation is a purely morphological one, but it is impossible to describe these organs of such unusual diversity without touching on their probable function and methods of working. The remarks made are suggestive and cry aloud for more work on this extremely interesting subject.

In conclusion, tribute must be paid to the very excellent technique and quality of the illustrations throughout. 